
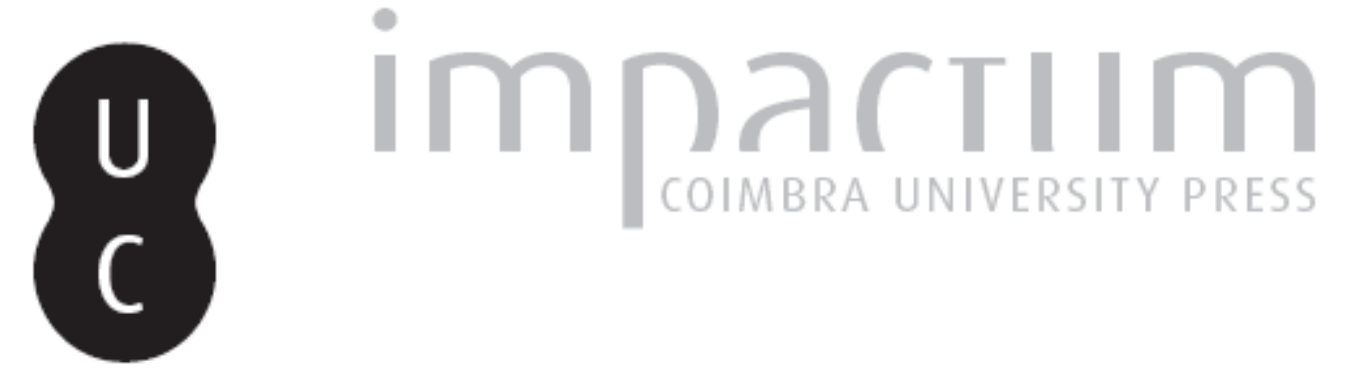

\title{
Geografia e geógrafos: institucionalização e consolidação da Geografia na Universidade de Coimbra
}
Autor(es):
Gama, António
Publicado por: Faculdade de Letras da Universidade de Coimbra
URL
persistente:
URI:http://hdl.handle.net/10316.2/32448
DOI:
DOI:http://dx.doi.org/10.14195/0870-4112_9_7
Accessed : $\quad$ 26-Apr-2023 13:41:11

A navegação consulta e descarregamento dos títulos inseridos nas Bibliotecas Digitais UC Digitalis, UC Pombalina e UC Impactum, pressupõem a aceitação plena e sem reservas dos Termos e Condições de Uso destas Bibliotecas Digitais, disponíveis em https://digitalis.uc.pt/pt-pt/termos.

Conforme exposto nos referidos Termos e Condições de Uso, o descarregamento de títulos de acesso restrito requer uma licença válida de autorização devendo o utilizador aceder ao(s) documento(s) a partir de um endereço de IP da instituição detentora da supramencionada licença.

Ao utilizador é apenas permitido o descarregamento para uso pessoal, pelo que o emprego do(s) título(s) descarregado(s) para outro fim, designadamente comercial, carece de autorização do respetivo autor ou editor da obra.

Na medida em que todas as obras da UC Digitalis se encontram protegidas pelo Código do Direito de Autor e Direitos Conexos e demais legislação aplicável, toda a cópia, parcial ou total, deste documento, nos casos em que é legalmente admitida, deverá conter ou fazer-se acompanhar por este aviso.

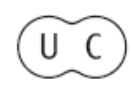



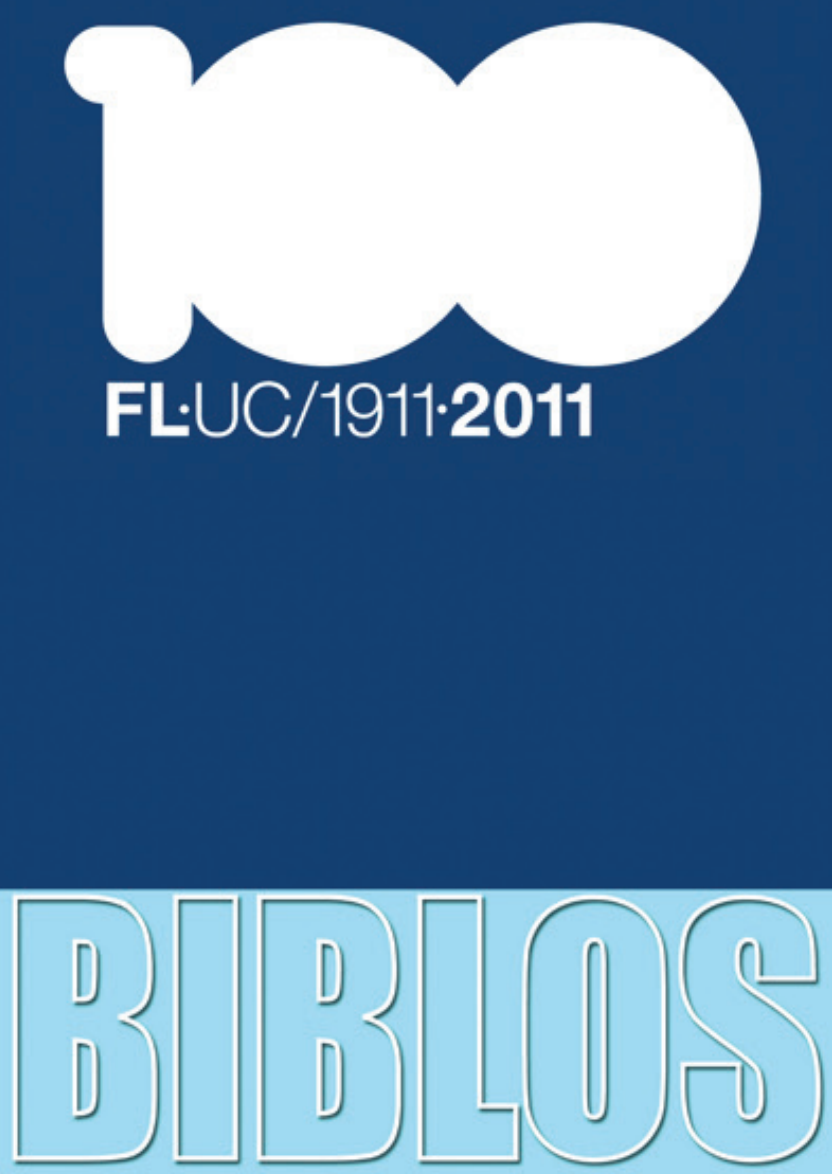

REVISTA DA FACULDADE DE LETRAS UNIVERSIDADE DE COIMBRA 


\title{
GEOGRAFIA E GEÓGRAFOS: INSTITUCIONALIZAÇÃO E CONSOLIDAÇÃO DA GEOGRAFIA NA UNIVERSIDADE DE COIMBRA
}

\begin{abstract}
Resumo
Nos cem anos da Faculdade de Letras da Universidades de Coimbra, igualmente assinala-se o passo decisivo na institucionalização académica da Geografia. Neste texto apontam-se razões da origens da institucionalização académica da disciplina, durante o século XIX, a exemplo de outros países europeus. Na constituição das Faculdades de Letras, implementada em 1911, após a Revolução Republicana de 1910, destaca-se a produção científica de nível superior em Geografia. Na sua institucionalização na Universidade de Coimbra, Anselmo Ferraz de Carvalho foi o seu grande impulsionador, processo continuado por uma crescente autonomização consumada no início da década de 1930, já com o empenho decisivo de Aristides de Amorim Girão, artífice da consolidação do prestígio académico e popular da Geografia instituída na Faculdade de Letras. Este processo foi continuado por outros, com destaque para Alfredo Fernandes Martins, cuja importância académica foi muito para além da obra que nos legou. Por fim esboçam-se, num breve epílogo, as mudanças após a revolução dos anos setenta.
\end{abstract}

Palavras-Chave: Institucionalização da Geografia, Licenciatura em Geografia; Geógrafos de Coimbra.

\footnotetext{
Abstract

On the centenary of the Faculty of Arts and Humanities at the University of Coimbra a decisive step towards the academic institutionalization of Geography is also celebrated. This paper examines the causes for the origins of this process, which took place throughout Europe during the nineteenth century.

When Faculties of Humanities were established in 1911, after the Republican Revolution of 1910, geographical scholarship stood out for its high scientific level. Anselmo Ferraz de Carvalho, at the University of Coimbra, was responsible for the first great impulse given to Geography. This process led to an increasing autonomy of the field, which was achieved in the early 1930s due to the decisive commitment of Aristides de Amorim Girão, who
} 
played a crucial role in the consolidation of the academic and public prestige of Geography at the Faculty of Arts and Humanities. This process was continued by others, especially Alfredo Fernandes Martins, whose academic significance went far beyond the work he left us. The article concludes with a brief epilogue, which surveys the changes following the revolution of the seventies.

Keywords: Institutionalization of Geography, Geography Degree, Coimbra's Geographers. 


\section{A Institucionalização da Geografia na Universidade}

Nos cem anos de Geografia em Coimbra, que o são igualmente das Faculdades de Letras das Universidades de Lisboa e Coimbra, assinala-se um passo decisivo na institucionalização académica da disciplina.

As razões que estiveram na origem da institucionalização da Geografia, em bom número de países europeus, durante o século XIX, há que buscá-las, segundo Horacio Capel, não tanto na lógica interna do conhecimento científico, como na acção de outros factores. Entre esses factores, que levaram à criação de uma disciplina de Geografia na Universidade, deve ser sublinhado o facto de a geografia aparecer nos programas do ensino primário e secundário e a correspondente necessidade de formar professores (Capel, 1981, 80). Desde o final do século XIX, assistiu-se, por conseguinte, em alguns países da Europa, a uma muito forte a pressão para a institucionalização da Geografia nos centros de ensino superior em razão da necessidade de formar professores com preparação específica para leccionar a disciplina que as reformas pedagógicas dos níveis primário e secundário exigia o qual se traduziu, sem dúvida, no factor decisivo para a aparição e afirmação do processo de criação de cursos de Geografia (Capel, 1981, 21).

Contudo, não se deve esquecer a crescente popularidade da disciplina desde a segunda metade do século XIX, em diversos meios sociais, associada à expansão colonial levada acabo por alguns países europeus, de que a criação das Sociedades de Geografia foi símbolo, como o caso da Sociedade de Geografia de Lisboa, em 1875.

São portanto mais os factores sociais que explicam a institucionalização e a aparição de uma comunidade científica de geógrafos, assim como são eles que explicam muitas das características que a ciência adoptou, nomeadamente a sua situação na Universidade.

No caso português, a exemplo do que acontecia nas universidades francesas, ficou incluída nas Faculdades de Letras. Havia já um precedente, pois tinha sido criada no Curso Superior de Letras, em Lisboa, em 1904, uma cadeira de Geografia e atribuída por concurso ao médico professor da Escola de Medicina Tropical, Francisco Xavier da Silva Teles (Ribeiro, 1976).

Em Portugal, na sequência da Revolução Republicana de 1910, a moderna produção científica de nível superior no campo geográfico passou a estar relacionada com a nova organização do ensino superior, 
implementada em 1911, com a constituição das Faculdades de Letras. Criada a Faculdade de Letras da Universidade de Coimbra, em substituição da Faculdade de Teologia, pelo Decreto de 19 de Abril de 1911, e de harmonia com o disposto no seu $\mathrm{Art}^{\circ}$ 31, foi eleito para a sua direcção o Dr. António de Vasconcelos, que transitava da antiga Faculdade. A proposta de reorganização apresentada por este, uns meses depois, envolvia uma reestruturação de todos os campos do saber. $\mathrm{Na}$ proposta, que foi aprovada por unanimidade, constavam os grupos, e os nomes dos responsáveis por cada um deles, que viriam a constituir a orgânica da Faculdade de Letras da Universidade de Coimbra. Para o $5^{\circ}$ grupo, o de Geografia, foi designado professor ordinário o Dr. Anselmo Ferraz de Carvalho, professor da Faculdade de Ciências, fazendo parte de uma secção com a História. Esta secção de ciências históricas e geográficas veio a constituir uma parte da orgânica da Faculdades de Letras, em que além das disciplinas históricas, foram instituídos os seguintes ensinamentos de Geografia: Geografia geral, Geografia física, na Faculdade de Ciências, Etnologia e Geografia política e económica, nas Faculdade de Letras.

No final do século XIX, a Geografia física adquire uma importância crescente, seguramente pela associação que se foi afirmando, ao longo do século, entre Geografia física e ciências da natureza, passando este ramo a ser considerado por muitos como a verdadeira Geografia. (Capel, 1981, 120). Isto veio a facilitar que geólogos e naturalistas viessem a ser incorporados, atraídos quer pelas oportunidades que se lhes ofereciam, quer pela capacitação que os geólogos possuíam para leccionar Geografia física.

A designação do Dr. Anselmo Ferraz de Carvalho (1878-1955) segue, pois, entre outras, a tendência de nomear especialistas em Geologia para a regência de cursos de Geografia. O cunho científico da nomeação é expresso por Amorim Girão quando diz que Ferraz de Carvalho "foi na Universidade de Coimbra o grande renovador do ensino da Geografia na Universidade de Coimbra, vazado nos moldes da moderna investigação científica" (Girão, 1955).

Logo após ter assumido o encargo de inaugurar o ensino geográfico na Faculdade de Letras, foi no ano de 1912, em missão científica a alguns dos mais notáveis centros científicos, com o intuito de Estudar a organização pedagógica neste posta em prática, tanto pelo que respeita à Geografia como à Geologia (Girão, 1955). Das suas lições 
saíram publicadas duas obras, uma Geografia Geral, em 1914, e uma Geografia Física de Portugal, em 1915, com o precioso auxílio do seu então aluno Aristides de Amorim Girão. Mais tarde, em 1945, entre uma diversa e extensa bibliografia, publica ainda Contribuição para o estudo da Geografia de Portugal (Carvalho, 1945)

A importância da geografia no curso foi entretanto crescendo em alterações posteriores. Em 1926, foi criado o curso de Antropogeografia geral, onde se adivinha a influência da obra com o mesmo nome de Friederich Ratzel, e ainda um curso anual de Mineralogia e Geologia na Faculdade de Ciências. Foi, além disso, desdobrada a disciplina de Geografia de Portugal e Colónias em duas, Geografia de Portugal e Geografia Colonial Portuguesa. A par destas alterações, foi instituída a especialização em Ciências Geográficas, continuando, no entanto, a Geografia a ser associada à História, nos cursos de Licenciatura. $\mathrm{O}$ curso, que, inicialmente, tinha a designação de Bacharelato em Ciências Históricas e Geográficas, viu os seus sete primeiros alunos terminar o curso em 1915-1916, entre os quais estava Aristides de Amorim Girão, e que viria a ter um papel decisivo nos futuros desenvolvimentos. Logo transformado em Licenciatura, o curso de Ciências Históricas e Geográficas teve durante os anos vinte um reduzido número de Licenciaturas. Sendo, de 1918 a 1930, frequentado por 45 alunos, com destaque para o ano de 1921-22, frequentado por sete. Nos cursos de 1926 a 1930, vieram a salientar-se no domínio da geografia Carlos Alberto Marques, Virgílio Taborda e F. Falcão Machado. (Rebelo, 1986). Neste período, doutora-se Amorim Girão, com a dissertação A Bacia do Vouga - estudo geográfico (1922), e em 1925, apresenta-se a concurso para Assistente, com um trabalho de Geografia urbana, Viseu-estudo de uma aglomeração urbana.

A autonomização do ensino da Geografia veio a consumar-se no início da década de 1930, com a criação de uma licenciatura em Ciências Geográficas. Esta modificação deveu-se ao empenho de Amorim Girão, quando foi reconhecido que esta associação entre História e Geografia, baseada na organização das universidades francesas e suíças, apresentava alguns inconvenientes. Conforme nos narra Amorim Girão em L'Evoluzione degli studi geografici in Portogallo (Girão, 1956). O processo de autonomização tem origem, sobretudo na insatisfação manifestada pelo Prof. Ferraz de Carvalho que, na sua qualidade de geólogo, notou sempre uma deficiência de preparação 
naturalística nos seus estudantes da Faculdade de Letras. Deficiência que Amorim Girão partilha quando relata que "seguindo nisto o meu Professor, pude reconhecer a necessidade de modificar este estado de coisas”. Esta reflexão é dada à estampa na revista Arquivo Pedagógico, que se publicava em Coimbra, onde veio a propor, em 1929, as duas soluções possíveis para um eficaz ensino da Geografia: organizar na Faculdade de Letras uma secção independente de Ciências geográficas, onde se ensinasse o curso complementar de Ciências naturais do Liceu; ou passar o ensino da Geografia para a Faculdade de Ciências, associando-o ao da Geologia, numa secção que poderia ser chamada de Ciências geológicas e geográficas. Acabou por ser a primeira solução que foi posta em prática em 1930.

A separação traduziu-se na reorganização das licenciaturas das Faculdades de Letras, criando duas licenciaturas novas, uma de Ciências Históricas e Filosóficas, outra de Ciências Geográficas. Os estudos de Geografia foram afastando-se da História ao mesmo tempo que procuravam melhores bases no âmbito das ciências exatas e naturais e que num novo plano de estudos tarduziu (Rebelo, 1986).

O ensino da Geografia, embora continuando a ser institucionalmente ligado à Faculdade de Letras, passou a ser leccionado nas faculdades de Letras e de Ciências, com uma organização muito semelhante ao da Universidade de Liège. Os estudantes nos primeiros dois anos frequentavam na Faculdade de Ciências, os cursos de Matemática, Física, Botânica e Zoologia ( $1^{\circ}$ ano), Geografia Matemática, Mineralogia e Geologia, Geografia física e Geofísica, Desenho topográfico e cartográfico ( $2^{\circ}$ ano); nos anos seguintes frequentavam, na Faculdade de Letras, os cursos de História da Geografia, Geografia geral, Etnologia, Antropogeografia e História de Portugal ( $3^{\circ}$ ano), e Geografia de Portugal, Geografia colonial portuguesa, Geografia política e económica, História dos descobrimentos e da colonização portugueses ( $4^{\circ}$ ano). Além do curso teórico, os estudantes seguiam cursos práticos, trabalho de laboratório e trabalho no terreno, durante as excursões de estudo. No final do curso, para o exame de licenciatura era exigida sempre a apresentação de uma dissertação ou trabalho original, elaborado pelo estudante e orientado por um professor.

Num balanço deste percurso inicial da Geografia nas Faculdades de Letras, Amorim Girão afirma que "o ensino da Geografia, na Faculdade de Letras de Coimbra, sob a direção do Prof. Ferraz de Carvalho, 
assim como em Lisboa, sob a orientação do Prof. Silva Teles, patenteou um decisivo esforço de renovação: difundiu ideias e suscitou vocações, determinando a publicação de alguns estudos geográficos de particular consideração." (Girão, 1940e 1956). O geógrafo alemão Herman Lautensach, referiu-se-lhe como "o surgir de uma nova era", quando pôs em relevo a diversidade de tendências, facto que o levou mesmo a falar de duas escolas geográficas portuguesas.

Com a institucionalização da licenciatura em Ciências Geográficas, em 1930, passou a ser exigida uma dissertação de licenciatura que incidia sobre um tema acordado com o professor orientador, exigência essa de que resultou um vasto conjunto de trabalhos que foram sendo apresentados até ao ano de 1974, altura em que foi extinta essa obrigação e substituída por um outra modalidade de trabalho de final de curso.

\section{A obra de Amorim Girão na consolidação da Geografia em Coimbra}

Aristides de Amorim Girão (1895-1960) teve um papel decisivo na fase inicial para a consolidação e o prestígio académico e popular da Geografia instituída na Faculdade de Letras em Coimbra que se continuou na sua consolidação.

O início da fase de consolidação corresponde à publicação de uma das suas obras de maior nomeada: o Esboço duma Carta Regional de Portugal. Publicada numa primeira versão em vários volumes da Revista da Faculdade de Letras, Biblos, em 1929, tem a sua segunda e definitiva versão em1933. Obra charneira da sua carreira, o Esboço viria a ser, com o tempo, uma das obras mais marcantes da geografia portuguesa. Tributária da obra farol da geografia francesa sobre geografia regional da autoria de Paul Vidal de la Blache, Le Tableau géographique de France, de 1903, estava "baseada em orientações mais modernas da ciência geográfica em que todos os elementos e factores que se inscrevem sobre a superfície do solo foram tomados em consideração" (Girão, 1933). O Esboço é, antes de mais, como aliás a obra de referência, uma tentativa de territorializar a nação, diferenciar o território em unidades regionais mais pequenas que as províncias (Ozouf-Marignier, et al., 1995). As diferentes unidades regionais são apresentadas como espaços encaixados segundo uma hierarquia de dois 
níveis: "as de nível superior, constituindo 13 unidades denominadas regiões, organismos que estão longe de corresponder às nossas antigas províncias, e as unidades menores que as constituem e que, à falta de nomenclatura especial, designaremos pelo nome de sub-regiões" (Girão, 1933). Em síntese, de um lado uma visão do país composto de diversidades regionais, por outro, a preocupação de definição dos conceitos e dos critérios com preocupações mais de índole académica que fundamentam o trabalho.

O Esboço situa-se, por conseguinte, como uma obra entre a Geografia física, a Geografia humana e a Geografia política, entre o mundo político e o mundo académico. Realizada no contexto político que caracterizou o inicio do Estado Novo, foi ao mesmo tempo um trabalho de índole política, com o propósito de servir de base a uma reforma administrativa e uma obra de teorização científica, em torno da conceptualização teórica e prática da noção de região. Com uma expressão muito para além do campo estritamente científico, desencadeou uma expressiva discussão de que a edição de 1933 dá em parte conta, e já discutida em outras publicações (Silva, 1990, Catroga, 2005).

A influência desta obra foi, no plano académico, mais duradoura pela sistematização conceptual e pela cartografia regional proposta, tornando-se referência para muitos dos trabalhos sobre estudos regionais, superando a fase inicial das delimitações ainda incertas e ofereceu uma conceptualização para o futuro do ensino da Geografia Regional. Assim, no início dos anos trinta, de 1930 a 1935, assistiu-se um período áureo, traduzido na conclusão de mais de trinta licenciaturas, com a maioria das teses a versarem sobre o tema. Se bem que se possa avalizar alguma da produção geográfica anterior a este período por alguns dos trabalhos produzidos por professores e por alguns alunos mais destacados e publicados na revista da Faculdade de Letras, Biblos, as teses de licenciatura tornaram-se desde então uma das fontes mais preciosas e abrangentes para fazer um balanço do devir dos estudos geográficos. Estes trabalhos permitem-nos fazer uma avaliação de quase meio século da produção geográfica quer no que se refere aos temas privilegiados e aos métodos como nos elementos que nos mostram para a identificação do país.

Numa publicação colectiva, editada em 2003, “As metamorfoses do País, retratos económicos e sociais do complexo mosaico regional português" (Almeida et al., 2003), onde se procedeu a uma análise 
destes trabalhos, pôde ser observada uma correspondência de certos temas a épocas. Definiu-se uma primeira fase que vai de 1930 ao final dos anos 1940. Nela predominam os temas regionais como preocupação central de estudo, apoiados crescentemente em trabalho de campo e num laborioso mas ainda incipiente trabalho de cartografia. Foi o tempo das experimentações e das sistematizações. Foi iniciada por alguns dos estudos regionais que se tornaram referencia de estudo em que o quadro regional era definido pelas bacias hidrográficas, como na obra de Amorim Girão, A Bacia do Vouga, de 1922.

Estes estudos de âmbito regional seguiram uma orientação que abarcava uma sucessão maior ou menor de assuntos que iam das características físicas da região delimitada a aspectos de população e povoamento, formas de habitat e materiais de construção e a aspectos dos modos de vida que se combinavam no que se designava como síntese regional.

Muitos deles foram apresentados como teses de Licenciatura, entretanto institucionalizadas. Estes estudos de âmbito regional envolvem uma sucessão de assuntos que se combinam numa síntese regional. Entre este género temático destacaram-se A Bacia do Côa de Carlos Alberto Marques de 1925, ainda antes da vigência das teses de licenciatura e a tese de licenciatura de Alfredo Fernandes Martins, O Esforço do Homem na Bacia do Mondego, de 1939. Esta, embora pelo título e pela estruturação seja dela tributária, acaba por trazer uma dimensão mais inovadora pelo alargamento à dimensão da ação humana, como ficou patente no pequeno opúsculo Resposta a um crítico (1941).

Amorim Girão assinala 1940 como uma data importante na atividade científica nacional em razão dos festejos dos Centenários, o oitavo centenário da Independência e os trezentos anos da Restauração. Abriu-se com esta data um período de progresso aos estudos geográficos, iniciado com um atlas nacional que se vem juntar aos que já se estavam publicados na Europa: o Atlas de Portugal (1941) e a primeira edição da Geografia de Portugal, ambos da sua autoria. Para além de outras publicações que se lhes seguiram o impulso que o Instituto de Alta Cultura vem a dar com a criação dos Centros de Estudos Geográficos, primeiro em Lisboa, em 1948, e depois em Coimbra, em 1949. Entre os apoios destaca-se a possibilidade de convidar investigadores estrangeiros, alguns dos quais vieram a realizar estudos de campo ao longo do país, com destaque para o Professor Pierre Birot, da Faculdade de 
Letras da Universidade de Lille, que além de estudos de morfologia regional, publicou sobre Portugal um volume de interesse (Portugal, Paris, Armand Colin, 1950), (Girão, 1956).

As actividades do Centro de Estudos Geográficos, anexo à Faculdade de Letras da Universidade de Coimbra, sob a direção de Amorim Girão, orientaram-se sobretudo para a Geografia Humana e a Cartografia, e par de estudos de Geografia Física. Deles, no início, foram publicados uma série de estudos sobre a população portuguesa, o mapa da densidade de população por freguesias e o mapa da divisão da propriedade rústica em Portugal.

Mais recentemente, além dos estudos regionais, começam a aparecer outros assuntos geográficos numa perspectiva mais temática, como os estudos de população nos anos 1940, análise geográfica do recente recenseamento de população e o estudo de âmbito agrícola e de outras actividades económicas, nomeadamente as indústrias extractivas e a pesca e portos.

É do início dos anos 50 a publicação do Boletim do Centro de Estudos Geográficos, do qual vieram a ser publicados cerca vinte e três números, onde se foram publicando os resultados de muitos dos trabalhos realizados. A perspectiva de Geografia defendida por Amorim Girão era então "estudar o homem como agente geográfico, considerando atentamente a ação modificadora que ele pode exercer sobre a superfície terrestre, induziu a minuciosas pesquisas nalgumas regiões portuguesas, sobretudo naquelas onde a exploração do ouro na época romana determinou mais profundamente transformações morfológicas na paisagem". Para ele, "a máxima preocupação de quem trabalhava neste Centro foi determinar o campo de investigação próprio da Geografia e os seus princípios metodológicos, assegurando o lugar que lhe cabe entre as outras ciências". Alguns novos trabalhos, mas sobretudo, reedições revistas de trabalhos anteriores, como as das suas obras maiores: o Atlas de Portugal, a Geografia de Portugal e a Geografia Humana.

A influência de Amorim Girão marcou de forma quase exclusiva durante este período pioneiro de lançamento e de consolidação dos estudos geográficos em Coimbra. A produção da sua obra de Geografia continuou até à morte em 1960, continuando a ser a figura proeminente tanto no curso de licenciatura em Coimbra como no Centro de Estudos Geográficos de Coimbra e na orientação do Boletim. 
Na sua vasta obra, para além dos diversos trabalhos de investigação sobre temas regionais e sobre a Geografia de Portugal, Amorim Girão dedicou-se desde cedo a construir uma longa reflexão sobre a geografia humana, de que se salientam A geografia moderna. Evolução, conceito, relação com outras ciências, de 1917, as Lições de Geografia humana, de 1936, a Geografia humana, de 1940, e um mais tardio, Acção do Homem e a Morfologia do Solo, de 1955, para além de outros textos mais pequenos e circunstanciais. É todo um percurso de vida e de reflexão que perpassa ao longo destas obras, primeiro acolhendo as ideias sobre uma geografia em renovação por essa Europa fora, nomeadamente Alemanha e França. São ideias que sustentavam o seu curso de Geografia humana na Universidade de Coimbra. Como refere: "Eu mesmo segui desde 1919 a orientação dos geógrafos da escola de Ratzel. Eram, então, para mim livro de cabeceira as Influences of Geographic environment de Ellen Semple, que pensei traduzir para português. As minhas Lições de Geografia humana, publicadas e 1936, denotam a primazia dada a esse livro." Mas depois veio "a reconhecer que, seguindo tal orientação, não andava a ensinar propriamente Geografia "ciência da Terra", mas sim Etnologia "ciência do Homem". E por isso, tive de modificar o ensino que fazia, passando a considerar especialmente no estudo geográfico a acção que o homem exerce sobre a Terra, de harmonia com as ideias de Vidal de La Blache, Jean Brunhes e Lucien Fèbvre" (Girão, 1957).

Em A geografia moderna. Evolução, conceito, relação com outras ciências, artigo publicado na Revista da Universidade de Coimbra, em 1917, que subintitula, ensaio de síntese, apresenta o âmbito da disciplina, primeiro mostrando a sua evolução, a seguir o modo como se deve entender, o conceito, em relação com as outras ciências. No final do texto, "depois de ter procurado delimitar o campo das investigações geográficas, pergunta-se, deverá o ensino da geografia conservar um conceito rígido? Claro que não: faz-se mister atender nos programas à necessidade de didáctica que às exigências do método, e abordar problemas que se liguem embora o seu lugar seja propriamente nos domínios de outras ciências" (Girão, 1917). Este artigo tem como referência um artigo publicado na mesma revista, dois anos antes, da autoria de Francisco Xavier da Silva Teles, professor da Faculdade de Letras da Universidade de Lisboa, com o título "O Conceito scientífico da Geografia" (Telles, 1915). 
As Lições de geografia humana, de 1936, continuam o programa de reflexões que iniciou com "A Geografia Moderna". E agora de forma mais profunda e sustentada, afirma mais claramente a nova concepção de Geografia que se fora consolidando no se espírito. A esta mudança não deve ter sido estranho um artigo publicado, em 1929, na Biblos, da autoria de Louis Papy, "Uma Sciência Nova: A Geografia Humana", em que este autor, depois de passar em revista o desenvolvimento das ideias de geografia, apresenta ao público português a escola francesa e o primado que nela tem Vidal de la Blache. Como sublinha, a esta escola "estava reservado preencher as lacunas da obra do autor alemão (Friedrich Ratzel), procurar os princípios práticos de observação, tirar aos métodos a sua demasiada rigidez". E continua dizendo que a Geografia humana "tem os seus princípios, e os seus métodos, as suas escolas, os seus mestres o seu focal", "sciência alguma é tão intuitiva e viva", e aponta um programa. "O verdadeiro geógrafo percorre, saco ao ombro, as estradas e os caminhos da planície, os atalhos ásperos da montanha, vive em contacto com os habitantes de uma região, operários ou rurais, e aprende a conhecer os "géneros de vida" a estudar como um certo grupo humano se adaptou a um certo território, como vive e evolui, a indagar quais são as suas necessidades, a sua mentalidade, as suas aspirações" (Papy, 1929).

No Prefácio das suas Lições de Geografia Humana, Amorim Girão justifica a obra, numa advertência preliminar que aparecera quando da sua primeira aparição na revista Biblos, em Janeiro de 1934: "No quadro de estudos professados nas Faculdades de Letras figura desde 1920, nas Faculdades de Letras o curso semestral de Antropogeografia Geral, que na reforma de 1930, passou a denominar-se Geografia Humana - um dos ramos que recentemente brotaram no velho tronco da Geografia, segundo a expressão de Vidal de La Blache", e como the tinha sido confiada a regência desse curso desde a sua criação, por não haver qualquer livro português e perante a solicitação dos alunos, decidiu-se lançar ombros à publicação das suas lições de Geografia Humana. "Verdadeiro benjamim entre as ciências da Terra e do Homem, esta disciplina é também das que ultimamente mais têm chamado as atenções do mundo culto, permitindo fazer uma sugestiva interpretação geográfica da história e aplicar ao mesmo tempo os princípios de uma rigorosa observação à análise dos fenómenos sociais" (Girão, 1936). 
As ideias mestras da disciplina são apresentadas na Introdução das Lições, assuntos que depois desenvolve nos restantes capítulos que compõem o livro. Começa por considerar "o elemento humano da geografia", baseando-se em que a "ideia mais fecunda para os modernos progressos da ciência geográfica é, sem dúvida, a de considerar a Terra como um organismo vivo, em contínuas mutações e evolução constante". Para ele, a Geografia é uma "ciência da interpretação dos traços fisionómicos da superfície terrestre", tendo o "descrever e explicar os traços fisionómicos da face da Terra como o objecto e fim principal da Geografia. Mas a face da Terra manifesta a sua fisionomia especial através dos fenómenos de superfície muito diversos; e para bem descrever e explicar esses fenómenos na expressão sintética em que eles se encontram associados à superfície do globo." (Girão, 1936).

Quanto aborda o método, diz que "a observação torna-se desta maneira a base essencial de todo o novo estudo, mas para a construção da "síntese geográfica" e para surpreender no mare magnum dos aspectos da superfície aquilo que há de essencial e de típico, essa observação tem de fazer-se em globo, abrangendo não apenas o que um vulgar observador pode alcançar com os seus olhos de qualquer ponto, mas ainda o que impressionaria um observador teórico, conforme o apresentado por Suess no princípio da sua Das Antlitz der Erde, elevando-se a alguma distância da superfície do solo" (Girão, 1936).

Em seguida, considera a Geografia como análise da paisagem e diz-nos que o geógrafo deve preocupar-se, acima de tudo com surpreender as diversidades da superfície, estabelecendo semelhanças e contrastes dos seus aspectos mais típicos. A Geografia será desta maneira, apoiando-se em Vidal de La Blache, "a análise da paisagem", procurando ver o que nela há de dominante, até ao ponto de imprimir a cada região uma fisionomia característica. Mas uma paisagem de um região é sempre o resultado de diferentes categorias de fenómenos que se inscrevem sobre a superfície do solo, as quais correspondem, afinal, a outros tantos ramos da Geografia.

A seguir, procede à distinção entre paisagens naturais e paisagens humanizadas. As casas, os caminhos, as estradas, os canais, os túneis, a cobertura vegetal, as culturas, as explorações mineiras, os portos, as fontes são factos geográficos tão dignos do nosso estudo e da nossa observação, como o relevo, a hidrografia e o clima. 
Por fim, sublinha o papel do homem entendido como agente modificador da superfície terrestre. "O homem pela sua simples presença basta para modificar a paisagem tanto ou mais que o animal ou a planta" numa frase tomada do comandante Rouch (Les traces essentiels de la Géographie humaine), ideia que sustentada igulamente em Jean Brunhes, "mais ainda que os elementos, e mais depressa ainda do que eles, o homem modifica os aspectos do globo", e em Camille Vallaux (1923) quando diz "os traços humanizados da paisagem tornam-se tão numerosos e, sobretudo, tão salientes que bem se pode dizer que eles" recobrem, deformam modificam e mesmo até ocultam inteiramente os acidentes da superfície "elaborando por assim dizer uma geografia nova da região em que se consideram". E prossegue, com traços de visão mística "o homem, colaborador na obra da criação", trata depois de enunciar a influência do meio físico sobre o homem, pois "seria fechar os olhos à realidade desconhecer a maneira como a actividade humana é constantemente influenciada pela natureza. Enuncia então a célebre frase de Ellen Semple, sua autora predileta do tempo da Antropogeografia: "o homem é um produto da superfície terrestre". O novo ponto de vista, "o homem, elemento essencial da diferenciação geográfica" sustenta-o com um passo de Vidal de La Blache de Les Principes de Géographie humaine, "civilizado ou selvagem, activo ou passivo, ou uma e outra coisa conjuntamente, o homem não deixa, nos seus diferentes estados, de fazer parte integrante da superfície do globo" (Girão, 1936).

Em 1940, regressa ao tema com a publicação de A Geografia humana. Nesta obra, sem trazer muito mais ao que apresentara antes, continua e consolida as ideias das Lições, alargando os horizontes quantos aos exemplos a outras paragens para além do território português, especialmente ao Brasil.

E retoma o tema da acção humana, já no final da vida, quando publica ainda um longo artigo Acção do Homem e a Morfologia do Solo, de 1955. Neste texto, partindo da critica da especialização exagerada, faz uma apresentação de casos que suscitam interpretações divergentes quando encaradas apenas por um ponto de vista. De novo ideia da acção humana é central no seu modo de ver ao longo das rubricas em que desenvolve a exposição: como a terra sai a cada momento das mãos do homem e a economia destrutiva como factor de modificação da face da terra, sublinhando que é "necessário tomar sempre em conta a acção do 
homem, não apenas como remodelador das paisagens, mas até como escultor das próprias formas do relevo" (Girão, 1955).

A preocupação com a delimitação do campo de estudos da Geografia está presente nestes textos e em outros de menor extensão. Naqueles, define e delimita a Geografia doutros domínios científicos, desenvolve temas, expõe conceitos e apresenta classificações. Nos de menor extensão, aparece a sua veia crítica, em apontamentos, recensões e balanços do que se faz na Geografia por esse mundo.

Desde o início, o eixo da sua reflexão centra-se numa ideia de ciência que procura clarificar num texto publicado no seu Boletim, "Definição acertada e necessária - Folheando as Revistas": "A ciência é uma só. Mas quando se ensina Geografia num curso superior, e se tem de indicar métodos de estudo, rumos e técnicas de investigação, ou quando se lança uma revista "geográfica", que deve sempre respeitar o campo próprio de outras revistas, julgo que já não se poderão descurar estas definições. Há toda a conveniência, direi mesmo toda a necessidade de delimitar campos de estudo. Os princípios que presidem à elaboração das Ciências da Natureza são bem diferentes dos que respeitam propriamente às Ciências do Homem. Importa distinguir bem, no interesse de todos" (Girão, 1957: 14-15).

A influência de Jean Brunhes, aparece ao longo de toda a sua obra a partir do início dos anos vinte, como ficou manifesto, em 1930, na alteração da designação da disciplina de Antropogeografia para Geografia Humana, termo grafado anos antes pelo geógrafo francês, quer depois nas suas Lições de geografia humana. Reafirma-a em 1958, em Fátima Terra de Milagre, quando se lhe refere como "o mago escritor geógrafo a quem coube fazer em La Géographie humaine a brilhante e aliciante sistematização dos princípios fundamentais desta ciência segundo as ideias do seu mestre Vidal de la Blache" (Girão et al. 1958).

O entendimente de que "a geografia é o estudo das diversidades da superfície da Terra. O seu objecto especial é a análise e a interpretação da paisagem. O seu fim último deve ser o estabelecimento de leis gerais - leis geográficas - respeitantes às relações recíprocas das coisas e dos fenómenos, que outras ciências estudam também mas que só ela pode examinar do seu ponto de vista especial" é dele devedor. E nesta reflexão ganha expressão "a explicação da paisagem geográfica, entendida como unidade, em que nenhuma ciência pode substituir a geografia" que 
colhe em Stanislas Pawlowsky. Para ele "as paisagens são complexos naturais e artificiais, são complexos naturais e artificiais de realidades, e fenómenos por tal maneira articulados imbricados e confundidos, ficando elas geralmente separadas por tão incaracterísticas zonas de transição, que é por vezes difícil reduzi-las a linhas simples, para bem as distinguir, delimitar e classificar. Não se torna sempre muito fácil surpreender numa região aquilo que as distingue de outras." (Girão, 1958).

A presença de Jean Brunhes revela-se ainda num texto de 1952, quando passa em revista algumas obras e ideias que traduzem uma renovação no âmbito da geografia francesa, discordando de alguns dos seus autores, aos quais manifesta as suas reservas, nomeadamente de Max Sorre. Essa resistência alicerça-a numa leitura muito própria dos mestres pioneiros da geografia francesa, mais Jean Brunhes que Vidal de la Blache. Isso, no entanto, não o impede de ser receptivo a ideias novas de que se destacam dois exemplos quer no que respeita a temas de uma geografia do fenómeno religioso ou à questão da aplicação da geografia.

O primeiro tema enuncia-o no texto de abertura de Fátima, Terra de Milagre, de 1958. Embora seguidor das ideias de Jean Brunhes, anota que este "apesar da notável cultura humanística que possuía, e da alta espiritualidade que informa tudo o que saiu da sua pena, considerou nos seus estudos apenas o homo faber e não chegou a tirar, por isso, todas as consequências da nova concepção antropogeográfica que tão sugestivamente apresentou. Na sua classificação dos factos essenciais da Geografia humana, bem oposta ao determinismo ratzeliano, não se preocupa com o "homem integral" (Maritain) e não foi até pôr em relevo o que de mais específico, e portanto de mais profundamente humano existe no homem - a sua qualidade de "animal religioso". Sugere a ideia de uma Geografia da religião, pela razão de que "onde a Natureza se mostra mais avara dos seus dons, e exige do Homem penosos esforços, é que vamos encontrar muitas vezes os povos que desempenharam grandes missões históricas", formulação onde ressoam ideias de Arnold Toynbee. E, termina sublinhando, seguindo Pierre Deffontaines, genro de Brunhes, "sacrifício dos homens surge como fonte de vida, tanto e por vezes mais do que a riqueza natural do solo" (Girão, 1958).

No segundo tema, quando aborda a questão da geografia aplicada, diz numa nota em 1956, entre as muitas que ia escrevendo no Boletim 
do Centro: "Em Portugal os estudos de Geografia aplicada começam a despertar a atenção. É no aspecto do ensino geográfico que tem especiais relações com os assuntos até agora versados no curso de Geografia humana. A orientação dada em Coimbra aos estudantes deste curso - a Geografia humana considerada como o estudo das modificações introduzidas pelo homem na face da Terra, quer dizer: o homem como factor essencial da paisagem - constitui, como bem poderá compreender-se, o melhor ponto de partida para aplicação pratica dos conhecimentos adquiridos". E logo remata, "muito nos regozijamos em saber que a nossa Direcção Geral dos Serviços de Urbanização tem em projecto a organização de uma colecção de mapas especialmente destinada a reunir toda a documentação necessária a tais serviços." E acrescenta: "far-se-á avultar aos olhos dos seus técnicos não só o estado actual das coisas, mas ainda a evolução recente dos fenómenos, onde possam vislumbrar-se até certo ponto as linhas da sua evolução futura. É uma tarefa de longo alcance, para a realização da qual os geógrafos terão necessariamente de dar o seu importante contributo.

À Geografia de Coimbra desse tempo ficaram ainda associados os nomes de Virgílio Taborda, Orlando Ribeiro, Jorge Dias e Fernandes Martins. A Virgílio Taborda, oriundo dos estudos históricos e filosóficos, que a morte levou prematuramente, ficou a dever-se o luminoso estudo regional O Alto Trás-os-Montes (Taborda, 1932). Alfredo Fernandes Martins, mais novo, e que cursou já Ciências geográficas, afirmou-se desde cedo com uma tese de licenciatura na senda dos estudos regionais, O Esforço do Homem na Bacia do Mondego, de 1939, e depois, em 1949, com a tese de doutoramento, marco no domínio da Geografia física, O Maciço Calcário Estremenho (Martins, 1949). Orlando Ribeiro, com uma fugaz passagem por Coimbra em 1943, deixou disso testemunho: "robustecido pelo trabalho de campo embora me agradasse o ambiente ainda provinciano de Coimbra, o convívio universitário e os problemas da região, fui transferido para Lisboa" (Ribeiro, 2003). Por fim, Jorge Dias, encarregado do curso Antropologia, que teve igualmente uma breve passagem por Coimbra, não sem ter empreendido uma recolha etnográfica que veio a constituir um acervo documental importante mas que não a teve a continuidade que mereceria.

Os anos cinquenta foram assim um tempo de consolidação da Geografia portuguesa, quer nacional como de reconhecimento internacional. Algumas circunstâncias favoreceram o progresso dos estudos 
geográficos em Portugal, como foi a realização do XVI Congresso Internacional de Geografia, em Lisboa, em 1949, organizado pelo Centro de Estudos Geográficos de Lisboa, favorecido pela condições geopolíticas do pós Segunda Grande Guerra. Deste encontro resultou o incremento dos contactos internacionais assim como contribuiu para estimular a atividade geográfica no país. Importantes foram ainda os contributos dos geógrafos portugueses para o Congresso, assim como na elaboração de um dos livros-guia das excursões, de que um geógrafo de Coimbra, Alfredo Fernandes Martins, foi autor: Le Centre litoral et le massif calcaire de estremadura.

Em Coimbra estava-se entre dois tempos: um consolidado pela herança anterior outro de uma renovação que se anunciava: ao mesmo tempo que Amorim Girão, nos últimos anos da sua vida, através do Boletim, ia deixando uma série de artigos, de notas e de recensões apontamentos acerca da geografia em mudança, não sem reservas, sentiase um ar de esperança numa renovação pelo impacto de novas ideias nomeadamente a influência do Congresso Internacional de Geografia, de 1949 provocou aliado ao crescendo dos contactos internacionais.

Após a morte de Amorim Girão, em 1960, coube a Alfredo Fernandes Martins, doutorado em 1949 e dotado de uma invulgar mestria da palavra, e que na década anterior participara já, de forma marcante, nos trabalhos da instituição, continuar o seu legado.

A terminar esta fase, ainda em vida de Amorim Girão, assistiu-se a um a nova renovação do plano de estudos. As mudanças operadas pela reforma de 1957 além de alterar a designação da Licenciatura, de Ciências Geográficas para Geografia, caracterizaram-se por uma maior importância da leccionação na Faculdade de Letras, com a inclusão de uma disciplina de Geografia Física, no $1^{\circ}$ ano, e outras no segundo. As disciplinas de Geografia além de aumentarem tomaram novas designações. Na Faculdade de Ciências leccionavam-se quatro disciplinas: os cursos gerais de Mineralogia, de Zoologia e de Botânica, no $1^{\circ}$ ano, e o de Geologia geral, no $2^{\circ}$, e ainda um curso semestral de Desenho Topográfico. De História constavam como disciplinas obrigatórias: Pré-História e História de Portugal I, no $3^{\circ}$ ano, e História da Expansão Portuguesa, no $4^{\circ}$, e uma série de disciplinas de opção, como História de Portugal II, História de Arte, Arqueologia, História da Civilização. O curso passava de quatro para cinco anos, reforçando a importância da tese de licenciatura, que passou a ser elaborada em 
regime de Seminário, constituindo a sua defesa uma prova de "acto final “. (Rebelo, 1986).

Este plano curricular continuou vigente apenas com ligeiras alterações, até 1974. Entre as novidades destaque-se a inclusão de uma Geografia aplicada.

\section{Alfredo Fernandes Martins: abertura de horizontes}

Alfredo Fernandes Martins (1916-1982) pode ser considerado um geógrafos de Coimbra com uma importância académica muito para além da obra que nos legou. Responsável pela formação de muitas gerações de estudantes que foram seus alunos, pela sua obra escrita e pela prática pedagógica, como outros já observaram, o último geógrafo completo de Coimbra.

Associando sólidos conhecimentos geográficos a uma vasta cultura, dissertava com igual à vontade e mestria sobre temas de Geografia Física ou de Geografia Humana, História ou de outras matérias. O cuidado posto na recolha e no tratamento da documentação, o rigor da observação para ilustrar a sua argumentação, a clareza e a elegância das apresentações escritas, a riqueza e precisão de linguagem são denominadores comuns que perpassam pela obra escrita e pelos testemunhos orais que nos legou. Esse legado foi evocado por uma das suas discípulas: "Porque se conservam na mente as suas aulas e conversas, se repetem as suas expressões, refletindo-o na memória com um fascínio sempre renovado? Porque aprendemos a aprender sem ambição, a crescer sem vontade de ser Grandes. E aprendemos que na universidade é rara esta lição" (Maria Eugénia Moreira in Almeida et al., 2006).

O percurso científico de Alfredo Fernandes Martins iniciado nos anos 30, evolui e atinge a maturidade acompanhando as vicissitudes das mudanças que a disciplina foi conhecendo. Discípulo de Anselmo Ferraz de Carvalho e Aristides de Amorim Girão que o põem-no em contacto com os textos da primeira geração dos modernos geógrafos franceses, então com um papel destacado na renovação da geografia europeia. Foi no âmbito da geografia física que almejou um reconhecimento que atravessou várias gerações, nomeadamente a partir de $O$ Maciço Calcário Estremenho Estudo de morfologia cársica, que apresentou 
como tese de doutoramento em 1949, que o tornou figura incontornável da geografia física potuguesa. A influência de autores franceses fundamentais neste campo de estudos patenteia-a nas referências a Emmanuel de Martonne e Henri Baulig, quanto aos temas gerais de Geografia física, a René Clozier, André Cholley e Henri Henjalbert, quanto aos de morfologia cársica. De De Martonne destaca-se o Traité de Géogaphie Physique, tradução para português em que participa, converte-se na referência maior para as aulas de Geografia física e num guia para a investigação. Outros devem ser referidos, como Henri Baulig, primeiro pelo Le Plateau Central de la France (et sa Bordure Méditerranéene - Étude de géomorphologie (de 1948), outra obra fundamental das suas lições e, depois, pelos Essais de Géomorphologie, ou como, na Pierre Birot, com quem partilhou alguns dos problemas da geomorfologia portuguesa, com as suas obras a serem recomendadas aos alunos, nomeadamente os Méthodes de la Morphologie e o Précis de la Géograhie Physique. Mais tarde, por meados de sessenta, vem o contacto com as obras de Jean Tricart, principalmente os Principes et méthodes de la Géomorphologie, a partir donde, aliada à geomorfologia estrutural, começa a falar de aspectos da geomorfologia climática.

Uma boa parte da investigação foi dedicado às terras do Centro de Portugal, desde a Bacia do Mondego, assunto para a dissertação de licenciatura, ao Maciço Calcário Estremenho, um estudo de morfologia cársica, à morfologia litoral, no estudo da evolução da costa e aos problemas dos Campos do Mondego e à descrição das paisagens humanizadas (Rebelo, 1992).

Se bem que mais conhecido pelas seus trabalhos de Geografia física não deixou de manifestar ao longo da sua vida, grande interesse por temas de Geografia humana e de História. Num primeiro momento, participa na discussão das duas questões maiores que estavam na ordem do dia afirmação da Geografia, como disciplina autónoma: a delimitação do seu domínio de estudo e a questão do método. À semelhança das seus pares da época, fiel à preocupação dos pioneiros da Geografia do início do século XX, procura afirmar urna clara delimitação do domínio de estudo da Geografia em relação a outras ciências. A fronteira com a Sociologia torna-se uma questão central na Geografia francesa na primeira metade do século XX, como, embora de forma mais ambígua também a delimitação do campo da Geografia com o da História foi objecto de atenção. Para isso, socorre-se novamente ao apoio de 
Jean Brunhes "Se é legítimo a alguns traçar estes factos apenas de um ponto de vista histórico porquê recusar a outros o direito de os tratar apenas do ponto de vista geográfico."

Para responder àquelas questões nucleares e ao modo do ser e fazer do geógrafo, apoia-se como o seu mestre em Jean Brunhes, cuja Geografia humana, editada em sucessivas versões desde 1910, fora, como vimos, leitura fundamental no ensino de Amorim Girão. É a ele que recorre para, em Resposta a um crítico (1941) questionar sobre o que é e em que consiste o espírito geográfico: "Quem é geógrafo sabe abrir os olhas e ver. Não vê quem quer. Em matéria de geografia física como em geografia humana a aprendizagem da visão positiva das realidades da superfície terrestres será o primeiro estádio e não o mais fácil. Por consequência, o método geográfico, em todos os domínios em que pode ser seguido, é um método que dá o primeiro lugar e o interesse principal ao estudo exacto, preciso, do que existe hoje. Antes de interpretar com base em testemunhos mais ou menos discutíveis os factos do passado, esforça-se por observar, agrupar e, enfim, se possível, classificar os factos do presente. É um método que tem um verdadeiro carácter positivo e científico".

Paul Vidal de la Blache revela-se na sequência da tradução de sua autoria dos Princípios de Geografia humana, em 1945. Na apresentação desta obra Alfredo Fernandes Martins escreve um texto intitulado "À guisa de prefácio", que tem o significativo subtítulo de "Geografia e História", onde prolonga a discussão do lugar e dos fundamentos da Geografia humana. O texto apresenta-nos de forma magistral o seu entendimento de Geografia humana, assim como o modelo de homem que a sustenta, a problemática das fronteiras entre disciplinas e os contributos mútuos acerca da definição e do papel do geógrafo. Para ele os geógrafos, "enquanto geógrafos, buscarão apenas e com humildade discernir o melhor que lhes for possível as relações, das sociedades com o meio, e isso no espaço e no tempo." (Martins, 1945). E expõe ainda, a pretexto da justificação da inclusão dos Princípios de Geografia Humana na colecção Marcha da Humanidade, mais detalhadamente a relação entre a acção humana e o quadro natural e define as premissas da interpretação em Geografia humana, a noção de modo de vida, que como tradução de genre de vie fixa em português. A lição de Vidal de La Blache atravessa o texto, não sem que na nota final se socorra ainda de Jean Brunhes para enunciar o que designa como as tarefas da Geografia humana. 
A sua evolução metodológica e temática nos assuntos de Geografia humana, que leccionou em diversas disciplinas, caracterizou-se por uma paulatina adopção dos temas sociais e económicos que as teses de licenciatura de que foi orientador foram revelando. No decorrer dos anos cinquenta e sessenta abrem-se novas perspectivas na investigação assistindo-se a uma incorporação de posicionamentos que o levam ao esbater as fronteiras disciplinares antes veementemente afirmadas e vigiadas. Entre outros aspectos impõem-se os temas sociais e económicos, nomeadamente com o projecto de uma geografia social, anunciado na editora Cosmos, infelizmente nunca concretizado. Estes levam ao repensar dos conceitos, nomeadamente o de modo de vida, mas também à necessidade de aprofundar temas e noções de natureza social, cada vez mais importantes para a compreensão do mundo moderno, como se assistia, nessa época, na geografia francesa, de onde vinham então as principais influências nomeadamente através da obra de Pierre George.

As suas aulas denotam uma vasto campo de leituras. Nestas, destacam-se, do início a meados do século XX, Camille Vallaux, colega de Jean Brunhes, os dois volumes de Géographie Sociale: Le Sol et L'Etat e La Mer. Leituras continuadas com Géographie et Sociologie de André Cholley e, principalmente, a obra de Max Sorre, num artigo dos Cahiers Internatianaux de Sociologie (1948) e principalmente o contacto com os Fondemmentes techniques de la Géographie humaine (1948) e dos Rencontres de la géographie et la sociologie (1957). Estas contribuíram para aprofundar os temas sociais, assim como enriqueceram a sua visão da geografia política. Depois, partir do final dos anos cinquenta, vieram as obras de Pierre George e o variado leque de assuntos que abordavam, desde a geografia da população à económica e a geografia social. La campagne, le fait rural à travers le monde e La ville le fait urban à travers le monde, sobre geografia rural e urbana, que conhece em primeiro lugar, ficaram patentes nas referências deixadas pelos alunos sob sua orientação nas teses de licenciatura, como por exemplo na ideia de cidade do autor francês: "ao mesmo tempo um facto histórico e um facto geográfico no sentido em que a sua forma é um compromisso entre o passado e o presente enquanto o seu conteúdo humano e a actividade dos seus habitanles quase integralmente marcados pelo signo do presente". 
Na sua evolução metodológica e temática são manifestas as suas afinidades com Pierre George e Jean Dresch, de cujos contactos nasceu interesse em estudar a emigração portuguesa em França, tema dos seus seminários nos anos setenta.

Um dos temas que mais o apaixonou, para além da Geografia física, foi a Geografia política, como ficou patente no curso que veio a poder leccionar após o 25 de Abril. De Friedrich Ratzel a Camille Valaux e Jean Brunhes do início do século, aos autores do pós-grande guerra, Max Sorre, Jacques Ancel e Jean Gottmann, e um ou outro mais recentes tornaram-se referências nas suas aulas.

A Geografia das Regiões Tropicais, curso que veio substituir a Geografia Colonial, designação mais consentânea com os tempos de descolonização e nas independências após a segunda Grande Guerra, foi por si leccionado durante vários anos. Aqui revelaram-se muitos dos seus dilemas de cidadão. Fascinado desde cedo pela ideia de exploração dos mundos, que está na razão de ser da geografia moderna, desde os tempos em que os europeus se lançaram pelo mundo, primeiro nas rotas de mar depois explorando os continentes. Uma geografia que do conhecimento dos mapas das terras passou ao conhecimento das gentes que as habitavam, materializada na "empresa da colonização, à qual a nossa época ligou a sua glória”, como disse Vidal de la Blache. Uma viagem que começou pelas terras de colonização e passou às regiões tropicais acabou por ser uma viagem com a própria geografia do seu tempo. A exploração de terras e de mares leva-o a interessar-se pelas expedições aos pólos e ao imaginário dos Mares do Sul.

Alfredo Fernandes Martins atravessou estes tempos não sem dilemas e expressou-os na escrita e na palavra. Num texto mais antigo, debruçou-se sobre a empresa da expansão dos portugueses pelo mundo, escrevendo um notável comentário intitulado Alguns reparos à classificação das colónias de George Hardy. Nos anos que lecionou estas matérias privilegiou sobretudo a geografia física, de um lado pelas suas preferências temáticas e pelo exotismo dos assuntos, em que encantou audiências. No que respeitava às matérias de Geografia humana converteu as obras de Pierre Gourou em guias preciosos desses cursos, primeiro, com o sedutor livrinho La Terre et l'Homme en Extreme Orient, depois com Les Pays tropicaux, les primcipes d'une géographie humaine et economique, que em sucessivas edições foi sempre a sua principal referência. Estes cursos ficaram atravessados 
pelo dilema de um militante de esquerda da sua época, dividido entre uma perspectiva civilizadora da colonização e o sonho de liberdade que as independências, como expressão dos sonhos de libertação dos povos colonizados. Embora não tenha traduzido em obra escrita o seu magistério veio a dar os seus frutos na renovação da geografia empreendida pelos seus alunos nos anos seguintes.

Ainda, no início dos anos 60, o conhecimento da Geografia francesa vem a ter um contributo marcante quando da fugaz passagem dos franceses Yves Leloup e Michel Drain, a quem se deve, em 1962, uma apresentação da moderna geografia francesa, com a publicação no Boletim de uma extensa nota com as principais obras de referência da bibliografia francesa, (Drain, 1962) e anos depois uma pequena obra sobre a Península Ibérica (Drain, 1964). Além destes, dois novos assistentes reforçaram o corpo docente de Geografia: José Manuel Pereira de Oliveira e Lucília de Andrade Gouveia que durante os anos sessenta asseguraram algumas das disciplinas aparecidas com a reforma de 1957.

São os anos do início uma lenta transformação, em que vão de par com uma modernização dos conteúdos e um maior aprofundamento nas técnicas de investigação. As teses de licenciatura elaboradas neste período refletem já outras preocupações, tanto nos temas como na visão da disciplina Mas o país estava também a mudar. os interesses viram-se agora para a indústria, nomeadamente a indústria transformadora, e as cidades, mas também as transformações que o veraneio vinha produzindo nos palheiros costeiros onde ainda persistiam as atividades de pesca. Mais tarde, nos finais de sessenta e durante a década de setenta, será o tema da emigração, impulsionado por Alfredo Fernandes Martins, o qual teve pouca expressão em publicações por, entretanto, ter sido retirada a obrigatoriedade de uma tese.

\section{Um breve epílogo: o curso das ideias após a revolução}

Os anos setenta marcam já uma mudança profunda nos horizontes da geografia portuguesa. Dois aspectos de particular importância na transformação do curso. Por um lado, a massificação no ensino universitário fez aumentar o número de alunos, e consequentemente, o número de professores que por mais novos trouxeram um potencial 
inovador maior, por outro, a transformações políticas desencadeadas pela Revolução de 1974, abriram novas possibilidades e novos horizontes no âmbito das universidades e a que os estudos de Geografia também não ficaram indiferentes. Novos planos de estudos, com novos curricula, mais atualizados em linha com o que se fazia em França, mas também no mundo anglo-saxónico, até então quase ignorado nas matérias versadas.

Anos agitados e de agitação de ideias, numa entusiasmada e entusiasmante procura de caminhos novos. Umas vezes de comum acordo, outras a contra corrente, as mudanças foram-se processando. Inspirados pela lições de insatisfação e de espírito crítico que o magistério de Alfredo Fernandes Martins tinha criado nos seus alunos. Alguns deles em início de carreira docente universitária, outros em final de licenciatura, abriram um campo de discussão que levou a uma reformulação do curso, com ajustamentos ao longo dos anos que se seguiram, umas vezes por revisões internas, outras por imposição ministerial, em vista a uniformizações dos planos a nível nacional ou por reação à mudança. Entre aqueles de maior empenho na criação de uma nova maneira de pensar a Geografia, destacaram-se José Manuel Pereira de Oliveira e Fernando Rebelo. Aquele, recém doutorado, pelo esforço com que procurou acompanhar aquilo que de novo se fazia lá fora, foi importante no domínio dos estudos urbanos, procurando suplantar os quadros tradicionais da sua formação, pela sua abertura em muitas e profícuas discussões, pela sua disponibilidade e pelo incentivo com que estimulou os mais novos. Este, mais jovem e a concluir a sua tese de Doutoramento, como portador de outras experiências com colegas de Lisboa, desenvolve o campo da Geografia Física e com uma forte intuição, uma linha de estudos que anos mais tarde se vem a configurar no tema geral dos riscos.

A cumplicidade frutuosa destes professores "levaram a bom porto a delicada tarefa da passagem de testemunho envolvendo gerações, métodos e objectivos de trabalho bem distintos". Por um lado na construção de um novo plano de estudos, por outro na redefinição de novos temas, de novos e horizontes pedagógicos e novas formas organizacionais.

O plano curricular de 1975 deu origem a uma refundação do elenco das disciplinas, com novas matérias, anunciadoras de novas orientações que em boa medida tiveram continuação, apesar de alguns sobressaltos regressivos, embora esta fase tenha durado apenas três anos. Foi um 
período febril pelos avanços realizados nos novos temas e nas práticas pedagógicas e em muitas das novas orientações de estudos que se abriram foram até então marginais, ou mesmo censuradas. Em 1978, por imposição ministerial nasce uma nova Reforma pelo Decreto 53/78. A nova organização curricular além de uniformizar os planos de curso de Geografia, nas três universidades, Lisboa, Porto e Coimbra, denotava uma visão regressiva e mais conservadora no plano curricular.

Contudo prevaleceram, em boa medida, no ensino de Geografia, muitas das novas perspectivas, em que se pretendia uma actualização com o que se fazia noutros países, nomeadamente em França e nos países anglo-saxónicos. Os planos de estudos foram sendo reformulados e adaptados de tal modo que a componente lectiva na Faculdade de Letras se tornou quase exclusiva.

O lançamento de uma publicação periódica, Cadernos de Geografia, iniciada em 1983, deu suporte e visibilidade à investigação, assim como a realização de um já numeroso número de encontros, colóquios e congressos propiciou um intercâmbio profícuo, tanto entre pares de outras universidades e instituições científicas como com os números antigos alunos que frequentaram a licenciatura em Geografia na Faculdade de Letras da Universidade de Coimbra.

Abrangendo um variado leque temático, foram-se sucedendo os estudos urbanos e regionais, os sócio-económicos, a par de um forte desenvolvimento da Geografia física, aliados a uma dimensão mais aplicada e a uma consciência como mais crítica. Outras matérias, como riscos, saúde, difusão das inovações, lazer e turismo vieram posteriormente renovar os interesses temáticos dos geógrafos do Departamento de Geografia. Ao mesmo tempo, foram adoptadas, de modo plural, novas perspectivas de estudo, desde a quantificação mais ou menos sofisticada às novas técnicas de cartografia a modos de ver de pendor humanista ou mesmo crítico, numa variedade de pontos de vista, nem sempre harmonizáveis.

Decorridos cem anos desde o início da institucionalização da secção de Geografia nas Faculdades de Letras e cerca de oitenta anos da sua autonomização com a criação da Licenciatura em Ciências Geográficas, Departamento de Geografia aglutina hoje cerca de três dezenas de docentes e investigadores, um número assinalável de doutorados e de publicações que revelam uma diversidade e uma pluralidade de olhares sobre temas geográficos. 


\section{Referências bibliográficas:}

ALMEIDA, António Campar de; GAMA, António; CRAVIDÃO, Fernanda Delgado; CUNHA, Lúcio; MARTINS, Paula Fernandes; JACINTO, Rui (2003) Fragmentos de um Retrato Inacabado. A Geografia de Coimbra e as metamorfoses de um País, Instituto de Estudos Geográficos, Coimbra.

ALMEIDA, António Campar de; GAMA, António; CRAVIDÃO, Fernanda Delgado; CUNHA, Lúcio; JACINTO, Rui (2006) Alfredo Fernandes Martins. Geógrafo de Coimbra, Cidadão do Mundo, Instituto de Estudos Geográficos, Coimbra.

CAPEL, Horácio (1981a) Filosofia y ciência en la Geografia contemporânea, Barcanova, Barcelona.

CAPEL, Horácio (1981b) Institutionalization of Geography and Strategies of Change, in STODDART, D.R. (org.) Geography, Ideology and Social Concern, Basil Blackwell, Oxford, (37-69).

CARVALHO, Anselmo Ferraz de (1914) Geografia Geral, lições feitas na Faculdade de Letras e coligidas por Aristides de Amorim Girão, Coimbra.

CARVALHO, Anselmo Ferraz de (1915) Geografia Física de Portugal, lições feitas na Faculdade de Letras e coligidas por Aristides de Amorim Girão, Coimbra.

CARVALHO, Anselmo Ferraz de (1945) Contribuição para o estudo da geografia de Portugal, Memorias e Notícias, Publicações do Museu Mineralógico e Geológico da Universidade de Coimbra, 22.

CATROGA, Fernando (2005) Geografia e Política. A querela da divisão provincial na I República e no Estado Novo, in FONSECA, Fernando Taveira da, O poder local em tempo de globalização, Imprensa da Universidade, Coimbra.

CLAVAL, Paul (1995) Géographie et Géographes, L'Harmattan, Paris.

CLAVAL, Paul (2006) Géographie régionale - de la région au territoire, Armand Colin, Paris.

DRAIN, Michel (1962) Pequena biblioteca geográfica (obras em francês), Boletim do Centro de Estudos Geográficos, Coimbra, vol. III, 19 (67-99).

DRAIN, Michel (1964) Géographie de la Péninsule Ibérique, PUF, Paris. 
GIRÃO, Aristides de Amorim (1918) A Geografia Moderna-Evolução Conceito - Relação com as outras ciências, Revista da Universidade de Coimbra, vol. VI, Imprensa da Universidade, Coimbra.

GIRÃO, Aristides de Amorim (1922) A Bacia do Vouga. Estudo Geográfico, Coimbra.

GIRÃO, Aristides de Amorim (1933) Esboço duma Carta Regional de Portugal, $2^{\text {a }}$ edição, Imprensa da Universidade, Coimbra.

GIRÃO, Aristides de Amorim (1936) Lições de Geografia Humana, Imprensa da Universidade, Coimbra.

GIRÃO, Aristides de Amorim (1940) Desenvolvimento dos Estudos Geográficos em Portugal, VIII Congresso de História da Actividade Científica Portuguesa, Congresso do Mundo Português, Tomo II, Lisboa, 1940 (531-534).

GIRÃO, Aristides de Amorim (1941) Atlas de Portugal, Coimbra (2 edição: 1958).

GIRÃO, Aristides de Amorim (1941b) Geografia de Portugal, Porto. (2a ediçao: 1949-50).

GIRÃO, Aristides de Amorim (1946) Geografia Humana, Porto.

GIRÃO, Aristides de Amorim e Morais, Custódio de (1950) Desenvolvimento dos estudos Geográficos em Portugal, Boletim do Centro de Estudos Geográficos, Coimbra, 1(7-12).

GIRÃO, Aristides de Amorim (1952) "Quo Vadis" Geografia Humana? Boletim do Centro de Estudos Geográficos, Coimbra, $4-5$ (1-16).

GIRÃO, Aristides de Amorim (1955) Prof. Doutor Anselmo Ferraz de Carvalho, Boletim do Centro de Estudos Geográficos, Coimbra, 10 e $11(1-3)$.

GIRÃO, Aristides de Amorim (1955b) Acção do homem e Morfologia do Solo, Boletim do Centro de Estudos Geográficos, Coimbra, 10 e 11 (38-68).

GIRÃO, Aristides de Amorim (1956) L'evoluzione degli studi geographiciin Portogallo, in Bolletino della Società Geográfica Italiana, Settembre-Ottobre, Roma.

GIRÃO, Aristides de Amorim et al. (1958) Fátima, Terra de Milagre, Boletim do Centro de Estudos Geográficos, Coimbra, 16 e 17().

HOLT-JENSEN, Arild (1999) Geograpy, History and Concepts, $3^{\mathrm{a}}$ ed., Sage Publications, London.

MARTINS, Alfredo Fernandes (1940) O Esforço do Homem na Bacia do Mondego. Ensaio Geográfico. Edição do Autor. Coimbra. 
MARTINS, Alfredo Fernandes (1941) A minha tese. Resposta a um critico. Edição do Autor. Coimbra.

MARTINS, Alfredo Fernandes (1945), À guisa de Prefácio, in Vidal de la Blache, Paul, Princípios de Geografia Humana, Cosmos, Lisboa. MARTINS, Alfredo Fernandes (1949) O Maciço Calcário Estremenho. Contribuição para um estudo de Geografia Física. Edição do Autor. Coimbra.

MARTINS, Alfredo Fernandes (1951) Esta Coimbra. Boletim Comemorativo do VI Aniversário do Clube Desportivo de Celas. (reimpressão em 1983), Cadernos de Geografia, 1 (35-78).

MARTINS, Alfredo Fernandes (1970) Curiculum Vitae, Edição do Autor, Coimbra.

OliVEIRA, J. M. Pereira de (1973) O Espaço Urbano do Porto. Condições Naturais e Desenvolvimento, I.A.C., C.E.G., Coimbra.

OLIVEIRA, J. M. Pereira de (1985) "In memoriam", Cadernos de Geografia, 4 (140-145).

OLIVEIRA, J. M. Pereira de (1983) A cidade do Porto como Centro Histórico, Cadernos de Geografia, Coimbra 2 (3-22).

OLIVEIRA, J. M. Pereira de (1994) Amorim Girão, Geógrafo, Cadernos de Geografia, Coimbra, 13 (118-124).

OLIVEIRA, J.M.Pereira de (2003) Da evolução dos estudos geográficos na Universidade de Coimbra, in ALMEIDA, António Campar de et al. Fragmentos de um Retrato Inacabado. A Geografia de Coimbra e as metamorfoses de um País, Instituto de Estudos Geográficos, Coimbra (23-31).

OUZOUF-MARIGNIER, Marie-Vic, ROBIC, Marie-Claire (1995) La France au seuil des temps modernes. Paul Vidal de la Blache et la régionalisation, L'Information Géographique, 59,(46-56).

REBELO, Fernando (1975) Serras de Valongo. Estudo de Geomorfologia, Coimbra.

REBELO, Fernando (1986) Reflexões sobre o ensino universitário em Portugal, Cadernos de Geografia, 5 (3-13).

REBELO, Fernando (2003), A investigação geográfica em Coimbra, in ALMEIDA, António Campar de et al. Fragmentos de um Retrato Inacabado. A Geografia de Coimbra e as metamorfoses de um País, Instituto de Estudos Geográficos, Coimbra (33-41).

REBELO, Fernando (2006, Fernandes Martins, um Geógrafo de Campo, in Almeida, António Campar de et al. (2006) Alfredo Fernandes 
Martins. Geógrafo de Coimbra, Cidadão do Mundo, Instituto de Estudos Geográficos, Coimbra

REBELO, Fernando (2008) A Geografia Física de Portugal na vida e obra de quato professores universitários, Minerva. Coimbra.

RIBEIRO, Orlando (1976) Silva Teles, Finisterra, 11 (29).

RIBEIRO, Orlando (2003) Memorias de um Geógrafo, J. Sá da Costa, Lisboa.

SILVA, Carlos Nunes (1986) Geografia Politica e Geografia da administração pública na obra de Amorim Girão, Biblos, 66. Faculdade de Letras. Coimbra.

TABORDA (1932) Alto Trás os Montes. Estudo Geográfico, Imprensa da Universidade, Coimbra. Reedição 1987, Livros Horizonte, Lisboa.

TELES, Francisco Xavier da Silva (1915) O Conceito Científico de Geografia, Revista da Universidade de Coimbra, Imprensa da Universidade, Coimbra.

VALLAUX, Camille (1925) Les sciences géographiques, Félix Alcan, Paris. 